\title{
Moderate-to-high intensity exercise with person-centered guidance influences fatigue in older adults with rheumatoid arthritis
}

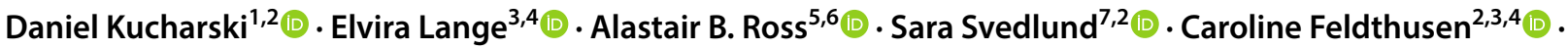

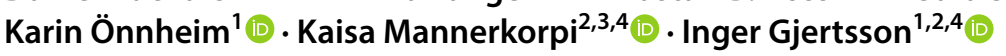

Received: 30 May 2019 / Accepted: 15 July 2019 / Published online: 20 July 2019

(c) The Author(s) 2019

\begin{abstract}
Fatigue is described as a dominant and disturbing symptom of rheumatoid arthritis (RA) regardless of the advances in pharmacological treatment. Fatigue is also found to correlate with depression. The objective was to evaluate the impact of moderate-to-high intensity, aerobic and resistance exercise with person-centered guidance on fatigue, anxiety and depression, in older adults with RA. Comparisons were made between older adults ( $>65$ years) with RA taking part in a 20-week moderate-to-high intensity exercise at a gym $(n=36)$ or in home-based exercise of light intensity $(n=38)$. Assessments were performed at baseline, at 20 weeks, and at 52 weeks. Outcomes were differences in Multidimensional Fatigue Inventory (MFI-20), Visual Analog Scale Fatigue (VAS fatigue), and Hospital Anxiety and Depression Scale (HADS). Analysis of metabolomics was also performed. The subscales "physical fatigue" and "mental fatigue" in MFI-20 and symptoms of depression using HADS depression scale improved significantly at week 20 in the exercise group compared with the control group. Exercise did not influence global fatigue rated by VAS or subscales "reduced motivation", "reduced activity" and "general fatigue" in MFI-20. No significant change was found on the anxiety index of HADS. The improvements in physical fatigue were associated with changes in the metabolism of lipids, bile acids, the urea cycle and several sugars. Moderateto-high intensity exercise with person-centered guidance decreased fatigue and improved symptoms of depression and were accompanied by metabolic changes in older adults with RA.
\end{abstract}

Keywords Arthritis $\cdot$ Rheumatoid $\cdot$ Patient-centered $\cdot$ Exercise $\cdot$ Fatigue $\cdot$ Depression $\cdot$ Anxiety $\cdot$ Metabolomics

Elvira Lange

elvira.m.lange@vgregion.se

Daniel Kucharski

daniel.kucharski@vgregion.se

Alastair B. Ross

Alastair.Ross@agresearch.co.nz

Sara Svedlund

sara.svedlund@gu.se

Caroline Feldthusen

caroline.feldthusen@vgregion.se

Karin Önnheim

karin.onnheim@microbio.gu.se

Kaisa Mannerkorpi

kaisa.mannerkorpi@neuro.gu.se

Inger Gjertsson

inger.gjertsson@rheuma.gu.se
1 Rheumatology and Inflammation Research, Institute of Medicine, The Sahlgrenska Academy, University of Gothenburg, Gothenburg, Sweden

2 The Sahlgrenska University Hospital, Gothenburg, Sweden

3 Department of Health and Rehabilitation, Institute of Neuroscience and Physiology, The Sahlgrenska Academy, University of Gothenburg, Box 455, 40530 Gothenburg, Sweden

4 University of Gothenburg Center for Person-centered Care, Gothenburg, Sweden

5 Department of Biology and Biological Engineering, Chalmers University of Technology, Gothenburg, Sweden

6 Protein and Metabolites Team, AgResearch, Lincoln, New Zealand

7 Department of Molecular and Clinical Medicine, Institute of Medicine, The Sahlgrenska Academy, University of Gothenburg, Gothenburg, Sweden 


\section{Introduction}

Rheumatoid arthritis (RA) is a chronic inflammatory disease characterized by joint pain, stiffness and inflammation of joint synovial tissue. In recent years, pharmacological treatments of RA have undergone revolutionary developments that have led to better control of inflammation and reduced joint destruction. The majority of the patients with RA, however, still suffer from fatigue [1], which they find to be a dominant and disturbing symptom [2-4]. There is currently no consensus definition of fatigue. Fatigue is acknowledged as a complex and subjective experience [5] and a commonly used description of fatigue is "an overwhelming sustained sense of exhaustion and decreased capacity for physical and mental work" [6]. Fatigue is multi-factorial; in patients with RA it is partially dependent on inflammation and production of pro-inflammatory proteins such as cytokines [7] and as in other conditions, can be related to inflammation-dependent anemia [8]. Fatigue correlates strongly with pain, depression [9-11] and sleep disturbances. Disability and psychosocial factors can also contribute [12]. The many effects of fatigue on the individual include disability, anxiety, reduced selfefficacy, feelings of helplessness and limitations in social functioning [13]. Unsurprisingly, a third of RA patients also suffer from depression.

Mechanisms explaining the interaction between inflammatory conditions and fatigue have remained largely elusive. Tools such as metabolomics can be used to explore the disease pathogenesis and generate new hypotheses for mechanisms based on the profile of small molecules in a sample. In blood plasma, the metabolites include organic acids, carbohydrates, amino acids and lipids, which together reflect many different metabolic pathways, and crucially, reflect the interaction between patient genetics, their environment, and the intervention. Metabolomics can be used to identify which pathways have been perturbed which is particularly relevant to patients with RA, for whom it has been shown that metabolites resulting from increased oxidative stress were most consistently associated with increased fatigue [14].

There is some evidence that increased physical activity can reduce fatigue and depression in younger patients with RA [15]. However, little is known about fatigue in relation to physical activity in older adults ( $>65$ years) with RA, an age group where the risk of increased in pain and fatigue in the implementation of an exercise program is a concern [16]. To overcome this hurdle we used a person-centered approach [17], with exercise developed together with the participant taking into account their limitations, resources and goals.

Here, we report the result of a secondary analysis of a randomized controlled multi-center trial, with the objective to study the effect of moderate-to-high intensity aerobic and resistance exercise during 20 weeks, on fatigue and symptoms of anxiety and depression in older adults with RA.

\section{Methods}

This is a sub-study of a randomized controlled trial that evaluated the effect of 20 weeks moderate-to-high intensity exercise on older adults with RA [18]. The study participants were recruited from the Rheumatology clinics at the Sahlgrenska University Hospital, Gothenburg and Skaraborg Hospital, Skövde, Sweden, using the Swedish Rheumatology Quality Register (SRQ).

The participants were randomized, in blocks of 6 subjects, by a person not involved in the examinations or interventions, using a computer-generated sequence concealed in sequentially numbered, sealed, opaque envelopes.

\section{Study groups}

The exercise group $(n=36)$ followed a gym-based exercise program with person-centered guidance from a physiotherapist three times a week together with light home-based exercise for 20 weeks. The exercise consisted of moderate-tohigh intensity aerobic and resistance exercise with a total of $27 \mathrm{~min}$ of aerobic exercise and 5 resistance exercises for large muscle groups. The active control group $(n=38)$ performed light home-based exercise for mobility, lower body strength and balance, but no gym-based exercise for 20 weeks. The exercise of both groups is described in detail elsewhere [18].

\section{Patients}

The participants were screened for eligibility by examination of their medical records, a telephone interview and a medical assessment. The medical assessment included physical examination, disease activity and blood samples. The flowchart of participant enrolment and follow-up, along with the details of tests of physical fitness, is presented elsewhere [18].

Inclusion criteria: RA according to the ACR 1987/ EULAR 2010 criteria; age $\geq 65$ years; disease duration $>2$ years; disease activity score $28<5$. 1 . Exclusion criteria: co-morbidities such as unstable ischemic heart disease or arrhythmia that might preclude moderate intensity exercise; joint surgery within the 6 months prior to inclusion; ongoing exercise of moderate-to-high intensity $\geq 2$ times/ week; inability to understand or speak Swedish; inability to participate in physical testing that involved walking or bicycling [18]. 


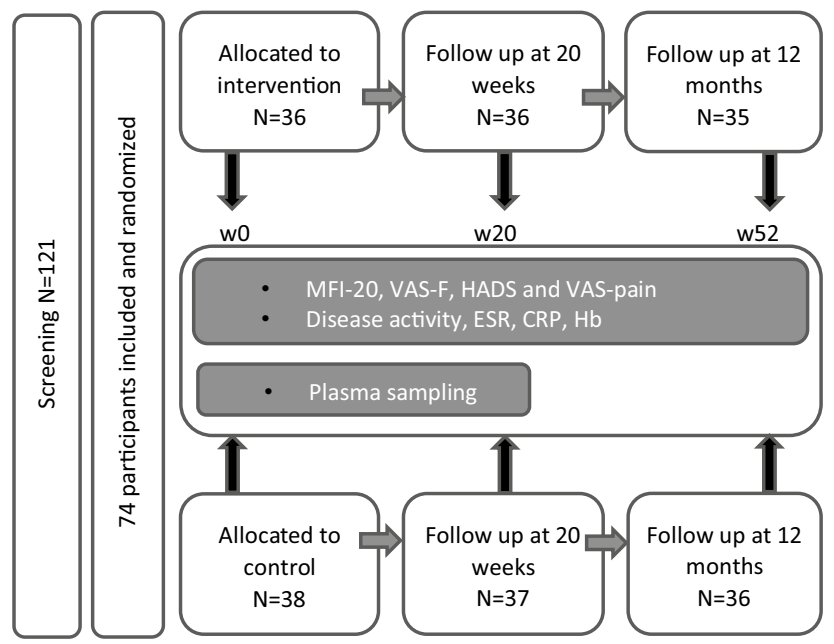

Fig. 1 Assessment points of the study with assessed variables and participant flow. MFI Multidimensional Fatigue Inventory, VAS-F Visual Analog Scale Fatigue, HADS Hospital Anxiety Depression Scale, VAS-Pain Visual Analog Scale Pain, ESR erythrocyte sedimentation rate, $C R P$ C-reactive protein, $H b$ hemoglobin

There were 74 older adults with RA included in the study (Fig. 1). The exercise group $(n=36)$ and the active control group $(n=38)$ were considered equal in sociodemographic data [18]. All participants were invited to a post-treatment examination after 20 weeks and $100 \%$ $(n=36)$ in the exercise group and 97\% $(n=37)$ in the active control group completed the test. At the 12 months follow-up the corresponding figures of attendance for assessment were $97 \%(n=35)$ in the exercise group and $95 \%(n=36)$ in the control group.

\section{Main outcome variable}

\section{Assessment of fatigue}

Subjective fatigue was quantified using the Multidimensional Fatigue Inventory (Swedish version) (MFI-20) [19]. Twenty statements were rated on a five-point Likert scale and divided into five subscales of fatigue: general fatigue, physical fatigue, mental fatigue, reduced activity, and reduced motivation. Scores range from 4 to 20 for each subscale, with higher scores indicating a higher degree of fatigue [19]. Participants' subjective experience of global fatigue was quantified using a Visual Analog Scale $(0-100 \mathrm{~mm})$-Fatigue (VAS-F). The participants rated global fatigue during the previous week considered due to RA on a scale of 0 (no fatigue) to 100 (the most severe fatigue possible) $[20,21]$.

\section{Assessment of anxiety and depression}

Anxiety and depression was assessed using the Hospital Anxiety and Depression Scale-Swedish version (HADS). The scale is built up of the subscales anxiety $(0-21)$ and depression (0-21). HADS contains 14 statements scored from 0 to 3 , higher scores being indicative of higher degrees of distress [22]. A score of eight or above on any of the subscales has been suggested as a valid cut-off to identify anxiety or depression disorders, respectively [22, 23].

\section{Measurement of plasma metabolomics}

Fasting baseline and 20-week plasma samples ( $n=48$ subjects) were used to understand potential metabolite associations with the intervention outcomes. Plasma metabolomics was measured using a previously validated gas chromatography-mass spectrometry (GC-MS) method [24]. In brief, 100 $\mu \mathrm{L}$ of plasma from fasting blood samples taken at baseline and at 20 weeks was extracted with $900 \mu \mathrm{L}$ methanol:water $(9: 1 \mathrm{v} / \mathrm{v})$, including a mix of internal standards, and a 200$\mu \mathrm{L}$ aliquot evaporated and derivatized using methoxymation and silylation. The metabolic profile was measured using GC-MS (Shimadzu TQ8030, Shimadzu Europa GmbH, Duisberg, Germany), and metabolites identified based on retention index and mass spectral matching.

\section{Other variables}

Disease activity was assessed using disease activity score 28 (DAS28) [25]. Erythrocyte sedimentation rate (ESR), $\mathrm{C}$-reactive protein (CRP) and hemoglobin ( $\mathrm{Hb})$ concentrations were measured by the accredited routine laboratories for clinical chemistry at Sahlgrenska University, Gothenburg, and at Unilabs, Skövde. Participants' objective experience of pain during the previous week considered due to RA was quantified using a Visual Analog Scale (0-100 mm) [21, 26]. Demographic data were collected via a standardized interview. For the analysis of metabolomics, correlations with the variable of maximal oxygen consumption $\left(\mathrm{VO}_{2} \max \right)$ presented elsewhere are made [18].

\section{Procedures}

The participants were assessed at baseline, after 20 weeks and at follow-up after 12 months. All assessors were blinded to the treatment groups.

The study complied with the Declaration of Helsinki and was approved by the Regional Ethical Review Board in Gothenburg (2014-11-24/790-14). Informed, written consent was obtained from the participants before the baseline examinations. The study was registered in ClinicalTrials.gov in March 19, 2015 (NCT02397798). 


\section{Statistical analysis}

Comparison between groups was performed with the Mann-Whitney $U$ test for non-parametric variables and Student's $t$ test for parametric variables using GraphPad Prism (GraphPad. San Diego. USA). $p<0.05$ was considered as statistically significant. For comparisons within groups the Wilcoxon signed rank test was used. Baseline correlations between DAS28 and outcome variables were performed with Spearman's correlation and a subgroup analysis was performed with DAS28 dichotomized as below 3.2 or 3.2 and above. The subgroup analysis was performed in the SPSS Statistics for Windows, Version 24.0 (IBM corp., Armonk, NY, USA).

Metabolomics data were log-transformed and corrected for baseline (post-intervention values minus baseline values) to correct for inter-individual differences. Metabolic feature reduction was done using orthogonal projection to latent structures discriminant analysis (OPLS-DA) and partial least squares (PLS) in Simca (Umetrics AB, Umeå, Sweden). Differences in metabolic response between groups were identified using the General Linear Model, including change in $V \mathrm{O}_{2} \max$ (as a proxy for compliance) and analytical batch as covariates.

Analysis were performed on the association between metabolic profile changes (week 20 minus baseline values), with change in physical fatigue and change in maximum oxygen consumption $\left(\mathrm{VO}_{2} \mathrm{max}\right)$ reported previously [18]. Associations were determined using Pearson's or Spearman's correlation coefficient depending on whether or not the data were normally distributed, and relationships reported if $p<0.05$.

\section{Results}

Demographics and clinical characteristics are presented in Lange et al. 2019 [18]. In brief, in the intervention group $75 \%$ were women with a mean age of 69.14 (SD 2.6) and in the control group, $76.3 \%$ were women, aged 70.11 (SD 3.10) at baseline. At baseline the variables MFI-20 general fatigue $(r=0.419, p<0.001)$, MFI-20 physical fatigue $(r=0.421$, $p<0.001)$ and the VAS-F variable $(r=0.454, p<0.001)$ correlated with DAS28.

Two participants in the exercise group and four in the control group used sedatives and the use of sedatives did not change during the study. At baseline two participants in the exercise group and one in the control group used antidepressant medication. After 20 weeks one of the participants in the exercises group had dimidiated the dosage and another two participants in the controls group had started on antidepressants (data not shown). 20-week exercise reduced fatigue in older adults with RA

The subscales of MFI-20 physical fatigue $(p=0.002)$ and mental fatigue $(p=0.048)$ was significantly reduced at 20 weeks in the exercise group when compared to the control group (Table 1). The remaining subscales of MFI-20, general fatigue, reduced activity and motivation, remained unaffected by exercise. Global fatigue reported using VAS-F did not significantly differ between exercise and control groups. The subgroup analysis based on dichotomization of DAS28 found no significant differences between the exercise and control group. Within the exercise group there was a significant difference in MFI-20 subscale physical fatigue both in the group with a low $(n=26$, median $\Delta=-2$, ICR: -3.25 ; $-1, p=0.001)$ and a moderate disease activity $(n=27$, median $\Delta=0$, ICR: $-1 ; 3, p=0.041$ ).

\section{0-week exercise alleviated symptoms of depression in older adults with RA}

At 20 weeks, there was a significant $(p=0.039)$ reduction in symptoms of depression in the exercise group compared to the control group (Table 1). At baseline one participant in the exercise group and two participants in the control group scored HADS depression above the cut-off of 8 points. After 20 weeks these three individuals still scored above the cut-off and further one of the control group participants (data not shown). The subgroup analysis showed that within the exercise group with a low disease activity, symptoms of depressions were significantly improved ( $n=27$, median $\Delta=-1$, ICR: $-1 ; 0, p=0.045)$ when compared to baseline. At baseline six participants of the exercise group and seven participants of the control group scored above the cut-off of 8 points on HADS anxiety. After 20 weeks three of these participants in the exercise group and one in the control group had lowered their score below the cut-off (data not shown). However, there was no significant difference between groups in anxiety (Table 1).

\section{0-week exercise did not influence pain, disease activity or inflammatory markers in older adults with RA}

The participants were considered to be equivalent in disease activity (DAS28) at baseline; 2.33 (SD 1.10) in the exercise group and 2.41 (SD 0.91) in the control group. After 20 weeks the disease activity was not significantly changed within or between groups with DAS28 in the exercise group at 2.27 (SD 1.05) and in the control group 2.27 (SD 0.92). Hb was also equivalent at baseline $131.4 \mathrm{~g} / \mathrm{L}$ (SD 11.6) in the exercise group and $131.1 \mathrm{~g} / \mathrm{L}$ (SD 13.6) in the control group) and did not significantly change after the intervention. The participants 
Table 1 Differences between groups in assessment measures at weeks 20 and 12 months compared to baseline

\begin{tabular}{|c|c|c|c|c|c|c|c|c|}
\hline & \multicolumn{3}{|c|}{ Intervention group $(N=36)$} & \multicolumn{3}{|c|}{ Control group $(N=38)$} & \multicolumn{2}{|c|}{$\begin{array}{l}\text { Between-group differ- } \\
\text { ences }\end{array}$} \\
\hline & Baseline & $\begin{array}{l}\text { Post-treat- } \\
\text { ment-base- } \\
\text { line }\end{array}$ & $\begin{array}{l}\text { Follow-up- } \\
\text { baseline }\end{array}$ & Baseline & $\begin{array}{l}\text { Post-treat- } \\
\text { ment-base- } \\
\text { line }\end{array}$ & $\begin{array}{l}\text { Follow-up- } \\
\text { baseline }\end{array}$ & $\begin{array}{l}\text { Post-treat- } \\
\text { ment-base- } \\
\text { line }\end{array}$ & $\begin{array}{l}\text { Follow- } \\
\text { up- } \\
\text { baseline }\end{array}$ \\
\hline & & $\Delta 20-0 \mathrm{w}$ & $\Delta 52-0 \mathrm{w}$ & & $\Delta 20-0 \mathrm{w}$ & $\Delta 52-0 \mathrm{w}$ & $p$ value & $p$ value \\
\hline \multicolumn{9}{|l|}{ MFI-20 } \\
\hline $\begin{array}{l}\text { General } \\
\text { fatigue }\end{array}$ & $8(6.3$ to 13.8$)$ & $-1(-3$ to 0$)$ & $0(-3$ to 1$)$ & $12(9.3$ to 13.8$)$ & $0(-3$ to 2$)$ & $0(-2$ to 2$)$ & 0.345 & 0.952 \\
\hline $\begin{array}{r}\text { Physical } \\
\text { fatigue }\end{array}$ & $9(6$ to 13$)$ & $\begin{array}{l}-2 * * *(-3 \text { to } \\
-0.8)\end{array}$ & $-2^{*}(-3.3$ to 1$)$ & $10(7.5$ to 13.5$)$ & $0(-1.8$ to 2$)$ & $0(-2$ to 1$)$ & $0.002 * *$ & 0.084 \\
\hline $\begin{array}{l}\text { Mental } \\
\text { fatigue }\end{array}$ & $8(5$ to 11$)$ & $0(-1.3$ to 4$)$ & $0(-3$ to 2$)$ & $9(4.5$ to 11$)$ & $0(0$ to 1$)$ & $0(-1$ to 2$)$ & $0.048^{*}$ & 0.466 \\
\hline $\begin{array}{l}\text { Reduced } \\
\text { motivation }\end{array}$ & $6(4$ to 9$)$ & $0(-1$ to 0.3$)$ & $0(-1$ to 1$)$ & 7 (4 to 9.5$)$ & $0(-1$ to 2$)$ & $1(-1 \text { to } 2)^{*}$ & 0.106 & 0.156 \\
\hline $\begin{array}{l}\text { Reduced } \\
\text { activity }\end{array}$ & $9(5.3$ to 13$)$ & $-1 *(-2$ to 1$)$ & $-1(-3$ to 0$)$ & 11 (7 to 13$)$ & $0(-1.3$ to 2$)$ & $0(-2$ to 2$)$ & 0.074 & 0.095 \\
\hline $\begin{array}{l}\text { VAS-F, } \\
0-100 \mathrm{~mm}\end{array}$ & $26(7.3$ to 50.5$)$ & $\begin{array}{l}-2(-11.5 \text { to } \\
4.8)\end{array}$ & $-1(-16$ to 8$)$ & $28.5(9.8$ to 42$)$ & $0(-11$ to 11.8$)$ & $-3(-10$ to 17$)$ & 0.355 & 0.707 \\
\hline \multicolumn{9}{|l|}{ HADS (0-21) } \\
\hline Anxiety & $2.5(0.3$ to 6.8$)$ & $-1(-2$ to 0$)$ & $0(-1$ to 1$)$ & $2(1$ to 6$)$ & $0(-1$ to 1$)$ & $0(-1$ to 1$)$ & 0.064 & 0.370 \\
\hline Depression & $2(1$ to 4$)$ & $0(-1 \text { to } 0)^{*}$ & $0(-1$ to 0$)$ & $2(1$ to 4$)$ & $0(-0.5$ to 2$)$ & $0(-1$ to 1$)$ & $0.039 *$ & 0.328 \\
\hline
\end{tabular}

Variables are presented as medians (IQR)

MFI Multidimensional Fatigue Inventory, VAS-F Visual Analog Scale Fatigue, HADS Hospital Anxiety Depression Scale

Delta values were compared using the Mann-Whitney $U$ test. Within-group comparisons were made with Wilcoxon

*Significant difference, $p<0.05$

**Significant difference, $p<0.01$

$* * *$ Significant difference, $p<0.001$

were considered to be equivalent in levels of inflammatory markers (CRP and ESR) and rated VAS-Pain at baseline [18] and there were no significant between- or within-group differences in these parameters at 20 weeks compared to baseline (data not shown).

\section{Changes to physical fatigue in $\mathrm{MFI}-20$ and $\mathrm{VO}_{2} \max$ were associated with several metabolic changes}

Based on targeted analysis of GC-MS data, 146 unique metabolites were identified in plasma samples from subjects in this study. Seventeen of these metabolites were significantly associated with changes in the MFI-20 physical fatigue scale, and aerobic capacity $\left(\mathrm{VO}_{2} \max \right)$ (Table 2$)$. These metabolites represent diverse compound classes and metabolic pathways monosaccharides, bile acids and metabolites related to lipid metabolism and the urea cycle.

\section{0-week exercise reduced circulating concentrations of some lipids in older adults with RA}

Twenty weeks of exercise led to decreases in plasma levels of 1-myristoyl-glycerol $(p=0.001), 24$-methylcholesterol $(p<0.001)$, cholesterol $(p=0.046)$, campesterol $(p<0.001)$ and $\alpha$-tocopherol $(p=0.003)$. Circulating levels of agmatine $(p=0.027)$ and phenylpyruvic acid $(p=0.020)$ were also increased in the intervention group (Table 3 ).

\section{2-week follow-up}

Withdrawal of the supervision of the exercise intervention program at 20 weeks resulted in the loss of the significant improvements in fatigue and depression recorded at that point in the study (Table 1). These findings coincide with diminished intensity and duration of exercise at 52 weeks [18]. Additionally, none of the outcomes from the assessments for HADS anxiety, VAS-P, or the remaining MFI-20 
Table 2 Correlations between change in physical fatigue or aerobic capacity, with change in metabolite concentrations between baseline and 20 weeks

\begin{tabular}{lllll}
\hline Metabolite & $\begin{array}{l}\text { Change in aerobic } \\
\text { capacity }\end{array}$ & $p$ value & $\begin{array}{l}\text { Change in physical } \\
\text { fatigue }\end{array}$ & $p$ value \\
\hline Arabinose & -0.333 & $0.034^{*}$ & \\
Lyxose & -0.348 & $0.026^{*}$ & \\
Pyruvic acid & -0.327 & $0.037^{*}$ & \\
Agmatine & -0.317 & $0.043^{*}$ & 0.302 & \\
Arginine & -0.410 & $0.008^{* *}$ & \\
Cysteine & -0.324 & $0.039^{*}$ & \\
Indole-3-acetic acid & -0.307 & $0.051^{*}$ & \\
$N$-Acetylglutamic acid & -0.320 & $0.041^{*}$ & & \\
Ribose & -0.353 & $0.024^{*}$ & & \\
Gluconic acid 1,5-lactone & 0.331 & $0.025^{*}$ & & \\
24-Methylcholesterol & & & 0.382 & \\
Alpha-tocopherol & & & 0.361 & $0.009^{*}$ \\
Campesterol & & & 0.403 & $0.014^{*}$ \\
Deoxycholic acid & & -0.304 & $0.006^{* *}$ \\
Glyceric acid & & 0.304 & $0.040^{*}$ \\
Quinic acid & & -0.314 & $0.040^{*}$ \\
Sorbitol-6-phosphate & & 0.314 & $0.034^{*}$ \\
\hline
\end{tabular}

Only statistically significant correlations are shown

Data on aerobic capacity from Lange et al. [18]

*Significant difference, $p<0.05$

$* *$ Significant difference, $p<0.01$

\begin{tabular}{|c|c|c|c|c|c|}
\hline \multirow[t]{3}{*}{ All participants } & \multirow{2}{*}{\multicolumn{2}{|c|}{$\frac{\text { Intervention group }(N=24)}{\Delta 20-0 \mathrm{w}}$}} & \multirow{2}{*}{\multicolumn{2}{|c|}{$\frac{\text { Control group }(N=24)}{\Delta 20-0 \mathrm{w}}$}} & \multirow[t]{3}{*}{$p$ value } \\
\hline & & & & & \\
\hline & Mean & SE & Mean & SE & \\
\hline 1-Myristoyl-glycerol & -3782.99 & 1528.857 & 6807.943 & 1528.857 & $0.001 * *$ \\
\hline 24-Methyl-cholesterol & -1790.35 & 725.679 & 4112.523 & 725.679 & $<0.001 * * *$ \\
\hline Agmatine & $-83,912.7$ & $25,804.98$ & $33,310.1$ & $25,804.98$ & $0.027 *$ \\
\hline Alpha-tocopherol & $-12,470.4$ & 5794.299 & $23,300.33$ & 5794.299 & $0.003 * *$ \\
\hline Campesterol & -1385.58 & 833.4642 & 4547.694 & 833.4642 & $<0.001 * * *$ \\
\hline Cholesterol & $-42,907.5$ & $23,636.28$ & $53,526.94$ & $23,636.28$ & $0.046^{*}$ \\
\hline Phenylpyruvic acid & $-19,582.9$ & 7740.779 & $17,587.55$ & 7740.779 & $0.020^{*}$ \\
\hline
\end{tabular}

$S E$ standard error

*Significant difference, $p<0.05$

$* *$ Significant difference, $p<0.01$

$* * *$ Significant difference, $p<0.001$
Table 3 Metabolites significantly affected by exercise intervention at 20 weeks compared to baseline

\section{Discussion}

To our knowledge, this is the first study to show that moderate-to-high intensity exercise reduces physical and mental dimensions of fatigue and has positive effects on symptoms of depression in older adults with RA, at the same time recording significant associations between these changes and differences in plasma concentrations of 
metabolites from a wide range of compound classes and pathways, reflecting the wide-ranging effects of effective exercise on metabolic status. The exercise intervention led to significant improvement in aerobic capacity, endurance and physical strength of participants [18], which have separately been found to reduce fatigue in people with RA or fibromyalgia less than 65 years of age [27, 28]. The observed effect of exercise on fatigue is to be contrasted with treatments that reduce disease activity profoundly, such as methotrexate and biologic/targeted synthetic disease modifying anti-rheumatic drugs (DMARDs), alone or in combination, as well as preventing joint destruction, but that only partly reduce [29] and seldom eliminate fatigue [1]. The participants in the present study were in remission or had low disease activity, but still scored clinically relevant fatigue (VAS $>20$ ) [12]. Their exercise affected neither disease activity nor inflammatory markers [18, 30], yet contributed to a clinically relevant [31] reduction of physical fatigue, suggesting that it is relevant to evaluate non-pharmacological treatment options against fatigue in older adults with RA.

The subgroup analysis indicates that the participants with a lower disease activity at baseline got the best effects of moderate-to-high intensity exercise on fatigue and depression. Disease activity has been found to correlate with fatigue [32], but has not been documented as a stronger predictor for fatigue in RA [12,33]. However, patients have described struggling with the unpredictability of the disease activity to be physically active [34] and reduced physical health is a barrier for exercise among older persons with RA [35].

Fatigue ratings by participants in this study were low relative to those reported by others $[3,36]$, one explanation for which could be selection bias; persons volunteering to participate in a study involving exercise 3 times a week are likely to be at the lower end of the fatigue spectrum for people with RA. Nonetheless there was a significant decrease in physical and mental fatigue directly after the intervention period (at 20 weeks) in the intervention group compared to the control group. Physical and mental fatigue are defined here by their respective MFI-20 subscales; "physical fatigue" records the person's feeling of physical wellness combined with their ability to perform different tasks, and is supposed to be related to significantly improved physical fitness in the participants in the intervention group [18]; "mental fatigue" on the other hand focuses on concentration and coping with thoughts. It is likely that the lessening of mental fatigue seen here is part of the alleviation of symptoms of depression rated with the HADS scale in the same participants. This provides at least a partial explanation of the positive effects of physical activity on depression found elsewhere [37-39], and reconfirms the link between fatigue and depression that has already been suggested [9]. A small minority of participants (3\% of the intervention group and 5\% in the control group at baseline) had symptoms of depression defined as HADS depression of more than 8 points. Nevertheless, the significant reduction of the HADS depression score in the intervention group at week 20 indicate that the mood of the participants was improved.

When the degree of exercise was reduced after 20 weeks the improvement in fatigue and symptoms of depression disappeared, along with enhanced physical fitness; only endurance was sustained to week 52 [18]. This outcome identifies a link between the supported maintenance of moderate-tohigh intensity exercise and its success in improving fatigue and depression, important determinants of quality of life of persons with RA [40], and should be taken into account in the design of therapies for the future.

We found no significant effects of exercise on either of the VAS-F or MFI-subscale "general fatigue" parameters, probably due to construction of the scales, as they rate global fatigue that may include several other feelings, such as pain and sleep. Neither were there significant differences between the two groups after the intervention in the subscales "reduced activity" and "reduced motivation", maybe reflecting a high degree of motivation in the selected cohort; in support of this possibility, the compliance with the study protocol was high and $98.6 \%$ of the participants completed the 20 weeks examination [18]. Both the selection of participants and the person-centered approach are likely to have contributed to this success [18]. Additionally, study participants were retired, and having fewer mandatory duties (working hours) and less demanding expectations from others might help older adults to cope with fatigue more easily [41].

The metabolomic profiling included in this study revealed changes attributable to the exercise intervention in eight of the identified metabolites, with only one of these metabolites also being significantly associated with the decrease in physical fatigue shown by the MFI-20 analysis. The metabolic changes found in the current study were largely related to lipid and specifically sterol metabolism, where circulating concentrations of some lipids were lower in the intervention group than in control group. Some of these are known to be diet-related (24-methylcholesterol, campesterol, and $\alpha$-tocopherol); the exercise intervention may have led to modifications in participants' food intake, or metabolism of these compounds may have increased. Exercise has elsewhere been found to raise concentrations of campesterol and sitosterol concentrations, in association with improved $V \mathrm{O}_{2} \max [42] . \alpha$-Tocopherol has been found to increase in high-intensity exercise, though rapidly returns to normal concentrations on resting $[43,44]$. As diet was not measured in this study, we can only speculate that physiological effects of exercise rather than dietary changed altered these lipids. Other studies using metabolomics to probe the effects 
of exercise interventions report effects on lipid metabolism, though often in addition to purine and central energy metabolism [45]. The association of pyruvic acid and ribose with $\mathrm{VO}_{2}$ max suggests that both purine and central energy metabolism pathways were impacted by the intervention, in addition to the urea cycle, as demonstrated by the relationship between both arginine and agmatine with change in $V \mathrm{O}_{2} \max$. These data suggest that the exercise intervention led to general metabolic changes that are consistent with the previous literature on exercise interventions, suggesting that RA does not alter metabolic response to exercise.

Especially for the metabolomics analysis, the low overall number of subjects and free-living nature of the current study are likely to be the cause of a considerable degree of inter-individual variation and potential confounding from lifestyle factors that have not been measured here. We also noted that there were significant gender effects which should be accounted for (data not shown). To control for this, future studies would benefit from including more subjects and using lipidomics analysis (methodology that focuses specifically on the lipid fraction of blood), since lipid metabolism appeared to be widely affected by exercise here, and many lipids play a role in inflammation pathways. This exploratory component of this study suggests that there are several metabolic changes related to improvement in physical fatigue in RA, and the use of such biomarkers will become increasingly useful in the tailoring of therapies including supervised exercise to individuals who are likely to see the greatest benefit.

Fatigue and depression are subjective symptoms with multi-factorial causes; for instance it has been observed that persons with RA suffer more with fatigue during the winter [46]. In documenting the lessening of fatigue and depression resulting from exercise, independent of disease status, this report emphasizes the importance of multi-modal approaches to both pharmacological and non-pharmacological aspects of treatment; understanding mechanisms may help to guide multi-pronged approaches to therapy for patients with RA.

\section{Limitations}

The studied population was highly selected [18] and therefore not representative for all older adults with RA. Most of the participants' had low disease activity and were positive about participating in a study regarding physical activity. Alongside this it would have been of interest to compare moderate-to-high intensity exercise not only with lowintensity exercise but with a control group performing no exercise. The study lacks logs of the participants' sleep and self-reporting sleeping questionnaires concerning the participants' sleeping habits that could have contributed to the understanding of changes in fatigue.
With the present study being a secondary analysis, power was calculated based on primary outcome of the primary analysis previously published [18]. The number of participants was considered to be sufficient for the aim of this analysis and the significant results indicate that they were.

\section{Conclusion}

Person-centered moderate-to-high intensity exercise decreased fatigue and lessened symptoms of depression in older adults with RA, improvements that were accompanied by metabolic changes. Our study strongly suggests that moderate-to-high intensity exercise should be implemented in standard care in older adults with RA. Further, to maintain the beneficial effects, the exercise needs also to be maintained.

Acknowledgements Open access funding provided by University of Gothenburg.

Funding This work was supported by the University of Gothenburg Center for Person-centered Care; the Health \& Medical Care Committee of the Regional Executive Board [VGFOUREG-66251]; Region Västra Götaland, ALF/LUA at Sahlgrenska University Hospital, [ALFGBG-4636751] and the Swedish Rheumatism Association [R-663361], Felix Neubergh foundation, Norrbacka-Eugenia foundation.

\section{Compliance with ethical standards}

Ethical standards The study complied with the Declaration of Helsinki and was approved by the Regional Ethical Review Board in Gothenburg (2014-11-24/790-14).

Informed consent Informed, written consent was obtained from the participants before the baseline examinations.

Open Access This article is distributed under the terms of the Creative Commons Attribution 4.0 International License (http://creativeco mmons.org/licenses/by/4.0/), which permits unrestricted use, distribution, and reproduction in any medium, provided you give appropriate credit to the original author(s) and the source, provide a link to the Creative Commons license, and indicate if changes were made.

\section{References}

1. Chauffier K, Salliot C, Berenbaum F, Sellam J (2012) Effect of biotherapies on fatigue in rheumatoid arthritis: a systematic review of the literature and meta-analysis. Rheumatology (Oxford) 51(1):60-68

2. Feldthusen C, Bjork M, Forsblad-d'Elia H, Mannerkorpi K, University of Gothenburg Centre for Person-Centred C (2013) Perception, consequences, communication, and strategies for handling fatigue in persons with rheumatoid arthritis of working age-a focus group study. Clin Rheumatol 32(5):557-566 
3. Rupp I, Boshuizen HC, Jacobi CE, Dinant HJ, van den Bos GA (2004) Impact of fatigue on health-related quality of life in rheumatoid arthritis. Arthritis Rheum 51(4):578-585

4. Hewlett S, Cockshott Z, Byron M, Kitchen K, Tipler S, Pope D, Hehir M (2005) Patients' perceptions of fatigue in rheumatoid arthritis: overwhelming, uncontrollable, ignored. Arthritis Rheum 53(5):697-702

5. Primdahl J, Hegelund A, Lorenzen AG, Loeppenthin K, Dures E, Appel Esbensen B (2019) The Experience of people with rheumatoid arthritis living with fatigue: a qualitative metasynthesis. BMJ Open 9(3):e024338

6. Repping-Wuts H, van Riel P, van Achterberg T (2009) Fatigue in patients with rheumatoid arthritis: what is known and what is needed. Rheumatology (Oxford) 48(3):207-209

7. Klareskog L, Catrina AI, Paget S (2009) Rheumatoid arthritis. Lancet 373(9664):659-672

8. Aapro MS, Cella D, Zagari M (2002) Age, anemia, and fatigue. Semin Oncol 29(3 Suppl 8):55-59

9. Nikolaus S, Bode C, Taal E, van de Laar MA (2013) Fatigue and factors related to fatigue in rheumatoid arthritis: a systematic review. Arthritis Care Res 65(7):1128-1146

10. van Hoogmoed D, Fransen J, Bleijenberg G, van Riel P (2010) Physical and psychosocial correlates of severe fatigue in rheumatoid arthritis. Rheumatology (Oxford) 49(7):1294-1302

11. Matcham F, Rayner L, Steer S, Hotopf M (2013) The prevalence of depression in rheumatoid arthritis: a systematic review and meta-analysis. Rheumatology (Oxford) 52(12):2136-2148

12. Pollard LC, Choy EH, Gonzalez J, Khoshaba B, Scott DL (2006) Fatigue in rheumatoid arthritis reflects pain, not disease activity. Rheumatology (Oxford) 45(7):885-889

13. Musumeci G (2015) Effects of exercise on physical limitations and fatigue in rheumatic diseases. World J Orthop 6(10):762-769

14. Surowiec I, Gjesdal CG, Jonsson G, Norheim KB, Lundstedt T, Trygg J, Omdal R (2016) Metabolomics study of fatigue in patients with rheumatoid arthritis naive to biological treatment. Rheumatol Int 36(5):703-711

15. Cramp F, Hewlett S, Almeida C, Kirwan JR, Choy EH, Chalder T, Pollock J, Christensen R (2013) Non-pharmacological interventions for fatigue in rheumatoid arthritis. Cochrane Database Syst Rev (8):CD008322

16. Veldhuijzen van Zanten JJCS, Rouse PC, Hale ED, Ntoumanis N, Metsios GS, Duda JL, Kitas GD (2015) Perceived barriers, facilitators and benefits for regular physical activity and exercise in patients with rheumatoid arthritis: a review of the literature. Sports Med (Auckland, Nz) 45(10):1401-1412

17. Ekman I, Swedberg K, Taft C, Lindseth A, Norberg A, Brink E, Carlsson J, Dahlin-Ivanoff S, Johansson IL, Kjellgren K, Liden E, Ohlen J, Olsson LE, Rosen H, Rydmark M, Sunnerhagen KS (2011) Person-centered care-ready for prime time. Eur J Cardiovasc Nurs 10(4):248-251

18. Lange E, Kucharski D, Svedlund S, Svensson K, Bertholds G, Gjertsson I, Mannerkorpi K (2019) Effects of aerobic and resistance exercise in older adults with rheumatoid arthritis: a randomized controlled trial. Arthritis Care Res 71(1):61-70

19. Smets EM, Garssen B, Bonke B, De Haes JC (1995) The Multidimensional Fatigue Inventory (MFI) psychometric qualities of an instrument to assess fatigue. J Psychosom Res 39(3):315-325

20. Hewlett S, Dures E, Almeida C (2011) Measures of fatigue: Bristol Rheumatoid Arthritis Fatigue Multi-Dimensional Questionnaire (BRAF MDQ), Bristol Rheumatoid Arthritis Fatigue Numerical Rating Scales (BRAF NRS) for severity, effect, and coping, Chalder Fatigue Questionnaire (CFQ), Checklist Individual Strength (CIS20R and CIS8R), Fatigue Severity Scale (FSS), Functional Assessment Chronic Illness Therapy (Fatigue) (FACIT-F), Multi-Dimensional Assessment of Fatigue (MAF), Multi-Dimensional Fatigue Inventory (MFI), Pediatric Quality
Of Life (PedsQL) Multi-Dimensional Fatigue Scale, Profile of Fatigue (ProF), Short Form 36 Vitality Subscale (SF-36 VT), and Visual Analog Scales (VAS). Arthritis Care Res 63:263-286

21. Price DD, McGrath PA, Rafii A, Buckingham B (1983) The validation of visual analogue scales as ratio scale measures for chronic and experimental pain. Pain 17(1):45-56

22. Zigmond AS, Snaith RP (1983) The hospital anxiety and depression scale. Acta Psychiatr Scand 67(6):361-370

23. Bjelland I, Dahl AA, Haug TT, Neckelmann D (2002) The validity of the Hospital Anxiety and Depression Scale: an updated literature review. J Psychosom Res 52(2):69-77

24. Savolainen OI, Sandberg AS, Ross AB (2016) A simultaneous metabolic profiling and quantitative multimetabolite metabolomic method for human plasma using gas-chromatography tandem mass spectrometry. J Proteome Res 15(1):259-265

25. Prevoo ML, van't Hof MA, Kuper HH, van Leeuwen MA, van de Putte LB, van Riel PL (1995) Modified disease activity scores that include twenty-eight-joint counts Development and validation in a prospective longitudinal study of patients with rheumatoid arthritis. Arthritis Rheum 38(1):44-48

26. Englbrecht M, Tarner IH, van der Heijde DM, Manger B, Bombardier C, Muller-Ladner U (2012) Measuring pain and efficacy of pain treatment in inflammatory arthritis: a systematic literature review. J Rheumatol Suppl 90:3-10

27. Ericsson A, Palstam A, Larsson A, Löfgren M, BileviciuteLjungar I, Bjersing J, Gerdle B, Kosek E, Mannerkorpi K (2016) Resistance exercise improves physical fatigue in women with fibromyalgia: a randomized controlled trial. Arthritis Res Ther 18(1):176

28. Feldthusen C, Dean E, Forsblad-d'Elia H, Mannerkorpi K (2016) Effects of person-centered physical therapy on fatiguerelated variables in persons with rheumatoid arthritis: a randomized controlled trial. Arch Phys Med Rehabil 97(1):26-36

29. Weinblatt ME, Keystone EC, Furst DE, Moreland LW, Weisman MH, Birbara CA, Teoh LA, Fischkoff SA, Chartash EK (2003) Adalimumab, a fully human anti-tumor necrosis factor alpha monoclonal antibody, for the treatment of rheumatoid arthritis in patients taking concomitant methotrexate: the ARMADA trial. Arthritis Rheum 48(1):35-45

30. Andersson S, Lange E, Kucharski D, Svedlund S, Önnheim K, Bergquist M, Josefsson E, Lord JM, Mårtensson I, Mannerkorpi K, Gjertsson I (2018) FRI0084 Intense aerobic and resistance exercise reduces the frequency of peripheral blood regulatory cell populations in elderly patients with rheumatoid arthritis. Ann Rheum Dis 77:587-588

31. Nordin $\AA$, Taft C, Lundgren-Nilsson $\AA$, Dencker A (2016) Minimal important differences for fatigue patient reported outcome measures-a systematic review. BMC Med Res Methodol 16:62

32. Abdel-Magied R, Lotfi A, Ali F, Hamdy M (2015) Assessment of fatigue in rheumatoid arthritis and its relation to pain and disease activity measures. Egypt Rheumatol Rehabil 42(4):178-182

33. Feldthusen C, Grimby-Ekman A, Forsblad-d'Elia H, Jacobsson L, Mannerkorpi K (2016) Explanatory factors and predictors of fatigue in persons with rheumatoid arthritis: a longitudinal study. J Rehabil Med 48(5):469-476

34. Feldthusen C, Mannerkorpi K (2019) Factors of importance for reducing fatigue in persons with rheumatoid arthritis: a qualitative interview study. BMJ Open 9(5):e028719

35. Lange E, Palstam A, Gjertsson I, Mannerkorpi K (2019) Aspects of exercise with person-centred guidance influencing the transition to independent exercise: a qualitative interview study among older adults with rheumatoid arthritis. Eur Rev Aging Phys Act 16:4

36. Barendregt PJ, Visser MR, Smets EM, Tulen JH, van den Meiracker AH, Boomsma F, Markusse HM (1998) Fatigue in primary Sjogren's syndrome. Ann Rheum Dis 57(5):291-295 
37. Dunn AL, Trivedi MH, Kampert JB, Clark CG, Chambliss HO (2005) Exercise treatment for depression: efficacy and dose response. Am J Prev Med 28(1):1-8

38. Danielsson L, Papoulias I, Petersson EL, Carlsson J, Waern M (2014) Exercise or basic body awareness therapy as add-on treatment for major depression: a controlled study. J Affect Disord 168:98-106

39. Kelley GA, Kelley KS, Hootman JM (2015) Effects of exercise on depression in adults with arthritis: a systematic review with meta-analysis of randomized controlled trials. Arthritis Res Ther $17: 21$

40. Karimi S, Yarmohammadian MH, Shokri A, Mottaghi P, Qolipour K, Kordi A, Bahman Ziari N (2013) Predictors and effective factors on quality of life among Iranian patients with rheumatoid arthritis. Materia Socio-Medica 25(3):158-162

41. Nikolaus S, Bode C, Taal E, van de Laar MA (2010) New insights into the experience of fatigue among patients with rheumatoid arthritis: a qualitative study. Ann Rheum Dis 69(5):895-897

42. Varady KA, Ebine N, Vanstone CA, Parsons WE, Jones PJ (2004) Plant sterols and endurance training combine to favorably alter plasma lipid profiles in previously sedentary hypercholesterolemic adults after 8 wk. Am J Clin Nutr 80(5):1159-1166
43. Pincemail J, Deby C, Camus G, Pirnay F, Bouchez R, Massaux L, Goutier R (1988) Tocopherol mobilization during intensive exercise. Eur J Appl Physiol Occup Physiol 57(2):189-191

44. Bowles DK, Torgan CE, Ebner S, Kehrer JP, Ivy JL, Starnes JW (1991) Effects of acute, submaximal exercise on skeletal muscle vitamin E. Free Radic Res Commun 14(2):139-143

45. Evangelia D, Chris E, David GW (2014) The application of metabolomic profiling to the effects of physical activity. Curr Metabolomics 2(4):233-263

46. Feldthusen C, Grimby-Ekman A, Forsblad-d'Elia H, Jacobsson L, Mannerkorpi K (2016) Seasonal variations in fatigue in persons with rheumatoid arthritis: a longitudinal study. BMC Musculoskelet Disord 17:59

Publisher's Note Springer Nature remains neutral with regard to jurisdictional claims in published maps and institutional affiliations. 